(2) Open Access Full Text Article

\title{
Successful alternative treatment for relapsed adult acute lymphoblastic leukemia with dendritic cells- cytokine-induced killer cells combined with a rituximab-based regimen
}

This article was published in the following Dove Press journal:

OncoTargets and Therapy

\section{XiaoFang Xiao \\ XingNong Ye \\ Cheng $\mathrm{Xu}$ \\ Jian Huang}

Department of Hematology, The Fourth Affiliated Hospital of Zhejiang University School of Medicine,

Zhejiang, China
Correspondence: Jian Huang

Department of Hematology, The Fourth Affiliated Hospital of Zhejiang University School of Medicine, NI Shangcheng Road, Yiwu, Zhejiang, China

Email househuang@zju.edu.cn
Objective: Acute lymphoblastic leukemia (ALL) is a malignant disease characterized by the accumulation of lymphoblasts, and a poor prognosis for adults with ALL is closely associated with disease recurrence. Thus far, treatment approaches have been limited, particularly in patients who are unable to tolerate chemotherapy. In this study, we report an effective treatment for such patients.

Materials and methods: A 52-year-old man diagnosed with Ph-negative B-precursor ALL went into remission after inductive treatment. Unfortunately, when he subsequently relapsed, severe complications drove him to refuse intensive chemotherapy. Instead, he received a cycle of dendritic cells-cytokine-induced killer cells (DC-CIK) before chemotherapy.

Result: The patient tolerated rituximab in combination with a vincristine, daunorubicin, L-asparaginase, and prednisone regimen without complications, and was in remission after DC-CIK infusion. After consolidation chemotherapy, including rituximab followed by eight cycles of DC-CIK, the patient has been free of leukemia for 2 years since the relapse.

Conclusion: This case of relapsed ALL was successfully treated with DC-CIK combined with a rituximab regimen.

Keywords: relapsed, acute lymphoblastic leukemia, DC-CIK, rituximab

\section{Introduction}

Acute lymphoblastic leukemia (ALL) is an aggressive malignant disease characterized by the accumulation of lymphoblasts in peripheral blood and bone marrow. Adults, historically, have had a poorer prognosis than children, with a 5-year event-free survival of only $30 \%-45 \% .^{1,2}$ Twenty percent of adults with ALL do not achieve complete remission after induction therapy, and relapsed ALL in adults carries a dismal prognosis despite intensive treatment. ${ }^{3,4}$ Standard regimens seem to provide limited benefits in a subset of relapsed or refractory ALL. ${ }^{5}$ Recently, new strategies such as monoclonal antibodies, antibody drug conjugates, and immunotherapy have provided effective alternative treatments. ${ }^{6}$

The use of cytokine-induced killer cells (CIK) has been categorized as passive adoptive T cell immunotherapy. ${ }^{7}$ Dendritic cells-CIK (DC-CIK) has exhibited antitumor activity in a variety of hematologic malignancies, including acute and chronic myeloid leukemia ${ }^{8}$ and lymphoma, mainly in vivo. ${ }^{9}$ However, little data exist regarding the effects of DC-CIK in adults with relapsed B cell ALL. In the present study, 
rituximab combined with DC-CIK was administered in the case of an early relapsed B cell ALL patient, who could not tolerate intensive chemotherapy.

\section{Materials and methods}

A 52-year-old man first presented with persistent fever and weakness in May 2014. Blood analysis showed reduced white blood cell $\left(1.8 \times 10^{9} / \mathrm{L}\right)$ and platelet counts $\left(63 \times 10^{9} / \mathrm{L}\right)$. A bone marrow aspirate revealed $72 \%$ immature blast cells, and immunophenotypic analysis showed that the blast cells expressed CD10, CD19, CD22, CD79a, and human leukocyte antigen-D related cells. Cytogenetics showed a normal male karyotype. The $M L L$ gene rearrangement, and $B C R /$ $A B L 1$ and $E T V 6 / R U N X 1$ translocations were also negative. A diagnosis of B-lymphoblastic leukemia not otherwise specified was made based on the 2016 revision of the World Health Organization classification criteria. ${ }^{10}$

The patient received the standard VDCLP regimen consisting of vincristine, daunorubicin, cyclophosphamide, L-asparaginase, and prednisone. At first, he achieved complete remission with $3.5 \%$ blast cells in the bone marrow. However, severe side effects caused by induction therapy, including febrile neutropenia, hyperglycemia, and hepatic toxicity eventually followed. After the administration of high-dose methotrexate combined with L-asparaginase and MA (mitoxantrone combined with intermediate-dose cytarabine) consolidation therapies, neutropenia persisted for 2 months, during which he was affected by pulmonary infection, sepsis, and liver dysfunction. He refused to receive any maintenance therapy because of significant complications.

Six months later, the patient presented with fatigue and petechiae with a short CR1. His bone marrow with $31 \%$ blast cells was consistent with relapsed B cell ALL (CD19+, $\mathrm{CD}_{4}{ }^{+}, \mathrm{CD}_{4} 5^{+}$, and CD10 ${ }^{+}$; Figure $1 \mathrm{~A}-\mathrm{a}$ to A-d). Therapeutic approaches for this patient in such a poor performance status were limited. The option of DC-CIK was then adopted.

\section{DC-CIK culture and analysis}

As described previously, ${ }^{11}$ peripheral blood mononuclear cells from the patient was collected using a blood cell separator. The DCs and CIK cells were induced in vitro and then cocultured. Immunophenotypic changes were analyzed by flow cytometry. The MTT assay was used to evaluate the cytotoxic effect of DC-CIK cells against K562 cells. After a quality control assay, qualified DC-CIK cells were administered to the patient.

\section{Ethics statement}

This study was approved by the Ethics Committee of the Fourth Affiliated Hospital of Zhejiang University. Before collecting clinical isolates from the patient, we informed him
A-a

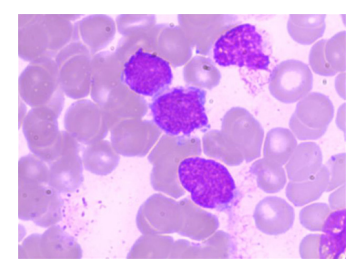

A-b

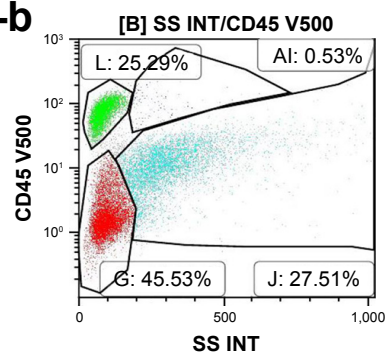

B-a

B-b
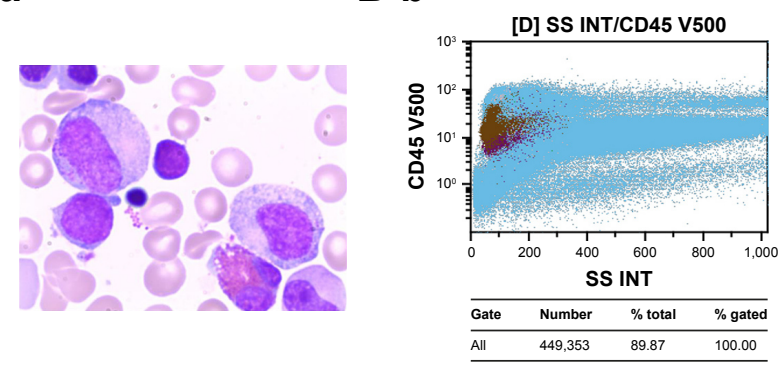

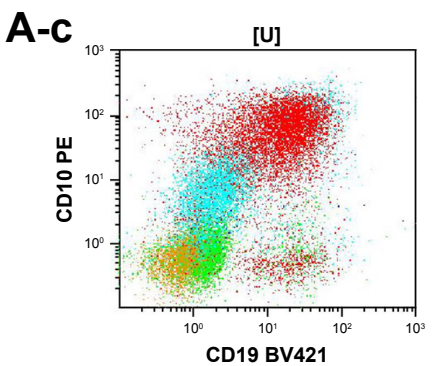

A-d

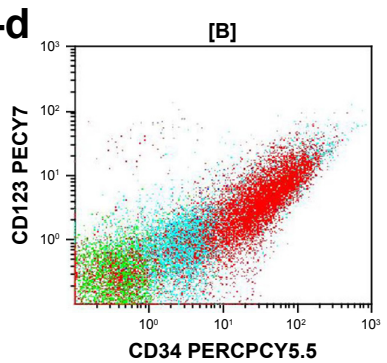

B-c

B-d
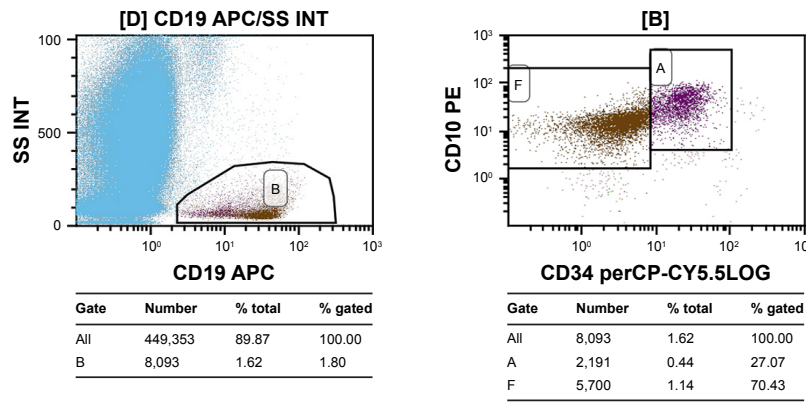

Figure I Bone marrow aspirate film in April 2015 showed relatively small blast cells (A-a). Scatterplot of flow cytometry immunophenotyping in ALL; there are expressions of CDI9, CD34 (A-b), CD45 (A-c), and CDI0 (A-d). While after infusion of DC-CIK cells and subsequent chemotherapy, bone marrow remission was observed in September 2017 (B-a), there are no blasts in scatterplot of flow cytometry immunophenotyping (B-b, B-c, B-d).

Abbreviations: ALL, acute lymphoblastic leukemia; DC-CIK, dendritic cells-cytokine-induced killer cells. 
of our research purposes and written informed consent was obtained. We advised that his specimens were for scientific purposes only, and the patient and specimens information were anonymous to protect the health, safety, and privacy of the patient. The patient also provided written informed consent for publication of the case details.

\section{Results}

At the first infusion, the proportion of $\mathrm{CD}^{+} \mathrm{CD}^{+} 6^{+}$cells among the DC-CIK cells was $42 \%$. The cultured DC-CIK cells inhibited the $\mathrm{K} 562$ cells by $58.3 \%$. The ratio of $\mathrm{CD} 8^{+}$ and $\mathrm{CD}_{56}{ }^{+}$cells in the peripheral blood of the patient after the first infusion was $42.23 \%$ and $53.04 \%$, respectively. During the infusion, no malfunctions in electrocardiography and no liver-renal abnormalities were observed. Subsequently, the rituximab combined with the vincristine, daunorubicin, L-asparaginase, and prednisone regimen was adopted, and a second remission was achieved without significant side effects.

Thereafter, four rounds of consolidation therapy including rituximab were administered, during which seven cycles of DC-CIK cells were infused alternately (each infusion comprised (4-6) $\times 10^{9}$ cells in a volume of $300 \mathrm{~mL}$ ). Before administration, cocultured DC-CIK cells were collected. The patient had no complaints during the infusion.

Thereafter, the patient received rituximab alone every 3 months for a year, and took thioguanine and methotrexate tablets at specific intervals of immunotherapy until March 11, 2017. Impressively, the patient has been in bone marrow remission since his last relapse (Figure 1B-a to B-d).

\section{Discussion}

Chemotherapy resistance and disease recurrence are impediments to the effective management of ALL patients. Although therapeutic options such as intensive chemotherapy, allogeneic hematopoietic cell transplantation, experimental treatments, and immunotherapy are available for ALL, management of relapsed ALL remains an urgent clinical challenge. In this case, the patient first refused one form of chemotherapy. Owing to cell immunotherapy, the patient responded well to reduction and chemotherapy.

Data pertaining to the response and efficacy of immunotherapy are limited. Yang et al reported on an 85-year-old patient with acute myeloid leukemia, who was successfully treated with ultralow decitabine and autologous CIK cells, ${ }^{12}$ suggesting that CIK cells may help to improve antileukemic potency and specificity. Furthermore, owing to the downregulation of regulatory $\mathrm{T}$ cells (Tregs) and the improvement of $\mathrm{T}$ cell immunity by DC-CIK, the quality of life in patients with malignant tumors is significantly elevated. ${ }^{7,13}$ In this case, the patient tolerated conventional chemotherapy well, which is consistent with the findings of previous studies.

Recent studies have demonstrated that rituximab antiCD20 monoclonal antibody therapy may play a critical role in the enhancement of CIK-mediated cytotoxicity to leukemia cells. ${ }^{14}$ An increase in the expression of cytotoxic factors in CIK cells and activation of the mitogen-activated protein kinase signaling pathway by rituximab are both possible mechanisms for the antiapoptotic effect on the proliferation of CIK cells. ${ }^{15}$ Furthermore, one study demonstrated that increased cytotoxicity of CIK cells, as induced by rituximab, was associated with increased expression of cytotoxic factors. ${ }^{16}$ In the present case, initiating DC-CIK therapy combined with a rituximab-based regimen helped to improve the therapeutic efficacy in a patient with refractory ALL. In addition, consolidation therapy that included DC-CIK and rituximab greatly enhanced progression-free survival.

\section{Conclusion}

To the best of our knowledge, this is the first report on DCCIK combined with a rituximab-based regimen for recurrent ALL. The use of DC-CIK is evidently safe and effective in relapsed ALL and could improve clinical symptoms in leukemia patients.

\section{Acknowledgments}

The research was supported by fundings from the Science and Technology Department of Zhejiang Province, China (2016C33160), the public technology research projects of Yiwu, China (2016-S-05), and the key medical discipline of Yiwu, China (Hematology, 2018-2020). Abstract has been available online in European Hematology Association (https://learningcenter.ehaweb.org/eha/2018/ stockholm/216186/jian.huang.successful.alternative. treatment.of.relapsed.adult.acute.html?f=menu=6*ce

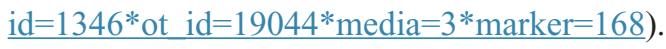

\section{Disclosure}

The authors report no conflicts of interest in this work.

\section{References}

1. Stock W, Johnson JL, Stone RM, et al. Dose intensification of daunorubicin and cytarabine during treatment of adult acute lymphoblastic leukemia: results of Cancer and Leukemia Group B Study 19802. Cancer. 2013;119(1):90-98.

2. Gökbuget N, Stanze D, Beck J, et al. Outcome of relapsed adult lymphoblastic leukemia depends on response to salvage chemotherapy, prognostic factors, and performance of stem cell transplantation. Blood. 2012;120(10):2032-2041. 
3. Kako S, Kanamori H, Kobayashi N, et al. Outcome after first relapse in adult patients with Philadelphia chromosome-negative acute lymphoblastic leukaemia. Br J Haematol. 2013;161(1):95-103.

4. O'Brien S, Thomas D, Ravandi F, et al. Outcome of adults with acute lymphocytic leukemia after second salvage therapy. Cancer. 2008; 113(11):3186-3191.

5. Gökbuget N, Dombret H, Ribera JM, et al. International reference analysis of outcomes in adults with B-precursor Ph-negative relapsed/ refractory acute lymphoblastic leukemia. Haematologica. 2016;101(12): 1524-1533.

6. Man LM, Morris AL, Keng M. New therapeutic strategies in acute lymphocytic leukemia. Curr Hematol Malig Rep. 2017;12(3):197-206.

7. Introna M. CIK as therapeutic agents against tumors. J Autoimmun. 2017;85:32-44.

8. Linn YC, Yong HX, Niam M, et al. A phase I/II clinical trial of autologous cytokine-induced killer cells as adjuvant immunotherapy for acute and chronic myeloid leukemia in clinical remission. Cytotherapy. 2012; 14(7):851-859.

9. Boeck CL, Amberger DC, Doraneh-Gard F, et al. Significance of frequencies, compositions, and/or antileukemic activity of (DC-stimulated) invariant NKT, NK and CIK cells on the outcome of patients with AML, ALL and CLL. J Immunother. 2017;40(6):224-248.

10. Arber DA, Orazi A, Hasserjian R, et al. The 2016 revision to the World Health Organization classification of myeloid neoplasms and acute leukemia. Blood. 2016;127(20):2391-2405.
11. Qu HQ, Zhou XS, Zhou XL, Wang J. Effect of DC-CIK cell on the proliferation, apoptosis and differentiation of leukemia cells. Asian Pac J Trop Med. 2014;7(8):659-662.

12. Yang B, Wang HT, Cai LL, et al. Successful management of acute myeloid leukemia transformed from myelodysplastic syndromes in an elderly patient aged over 80 years old by ultralow dose decitabine combined with amifostine and autologous CIK cells. Ann Hematol. 2014; 93(7):1233-1235.

13. Cappuzzello E, Sommaggio R, Zanovello P, Rosato A. Cytokines for the induction of antitumor effectors: the paradigm of cytokine-induced killer (CIK) cells. Cytokine Growth Factor Rev. 2017;36:99-105.

14. Pievani A, Belussi C, Klein C, Rambaldi A, Golay J, Introna M. Enhanced killing of human B-cell lymphoma targets by combined use of cytokine-induced killer cell (CIK) cultures and anti-CD20 antibodies. Blood. 2011;117(2):510-518.

15. Deng QI, Bai X, Lv HR, Xiao X, Zhao MF, Li YM. Anti-CD20 antibody induces the improvement of cytokine-induced killer cell activity via the STAT and MAPK/ERK signaling pathways. Exp Ther Med. 2015; 9(4):1215-1222.

16. Stroopinsky D, Katz T, Rowe JM, Melamed D, Avivi I. Rituximab-induced direct inhibition of T-cell activation. Cancer Immunol Immunother. 2012;61(8):1233-1241.
OncoTargets and Therapy

\section{Publish your work in this journal}

OncoTargets and Therapy is an international, peer-reviewed, open access journal focusing on the pathological basis of all cancers, potential targets for therapy and treatment protocols employed to improve the management of cancer patients. The journal also focuses on the impact of management programs and new therapeutic agents and protocols on

\section{Dovepress}

patient perspectives such as quality of life, adherence and satisfaction. The manuscript management system is completely online and includes a very quick and fair peer-review system, which is all easy to use. Visit http://www.dovepress.com/testimonials.php to read real quotes from published authors. 